\title{
Analisa Penyebab Kemacetan Dan Kecelakaan Jalan Raya Ngaliyan Kota Semarang Tanjakan Silayur
}

\author{
Heni Wulandari*1, Prasasta Samba G. W'2, Mudjiastuti Handajani3, \\ Agus Muldiyanto ${ }^{4}$ \\ Jurusan Teknik Sipil, Fakultas Teknik, Universitas Semarang \\ Jl. Soekarno Hatta, Tlogosari, Semarang, Jawa Tengah, Indonesia. \\ e-mail: *heniwulandari997@gmail.com
}

Received 29-10-2021; Reviewed 30-11-2021; Accepted 01-12-2021

Journal Homepage: http://ktj.pktj.ac.id/index.php/ktj

DOI: $10.46447 / \mathrm{ktj} . \mathrm{v} 8 \mathrm{i} 2.407$

\begin{abstract}
A traffic accident is a tragedy or accident that occurs on the road involving a motorized or heavy vehicle with other road users or without a vehicle. This incident caused the victim to suffer physical, health and material losses. Traffic accidents occur due to several factors such as human error or inadequate road conditions. Even traffic jams can also lead to traffic accidents. The problem of driving and road safety needs to be considered to reduce the number of traffic accidents that occur. This study was conducted to determine the factors that cause accidents, especially those caused by road conditions and traffic performance. The method used in the field observation research and using data on the number of accidents in 2018-2020 located on Jalan Raya Ngaliyan which was taken from the accident data of the West Semarang Police Traffic Unit. The level of road performance on Jalan Tanjakan Silayur Semarang City, at peak hours in the morning and non-peak hours during the day category $C$ and at peak hours in the afternoon category E. Damage to the flexible pavement surface on Jalan Tanjakan Silayur is dominated by the type of damage cracks, grooves, and bleeding. One of the factors that caused the accident was because the traffic signs were not optimal on the Jalan Tanjakan Silayur section.
\end{abstract}

Keywords: Accident, Traffic Accident, Traffic Congestion

\begin{abstract}
Abstrak
Kecelakaan lalu lintas merupakan tragedi atau peristiwa kecelakaan yang terjadi di jalan yang melibatkan kendaraan bermotor atau berat dengan pengguna jalan yang lain atau tanpa kendaraan. Peristiwa ini menyebabkan korban mengalami kerugian secara kondisi fisik, kesehatan, dan materi. Kecelakaan lalu lintas terjadi disebabkan beberapa faktor seperti human eror atau kondisi jalan yang tidak layak, Bahkan kemacetan lalu lintas pun juga dapat mengakibatkan kecelakaan lalu lintas. Permasalahan keselamatan berkendara dan jalanan perlu diperhatikan untuk mengurangi jumlah angka kecelakaan lalulintas yang terjadi. Penelitian ini dilakukan untuk mengetahui faktor penyebab kecelakaan khususnya yang dikarenakan kondisi jalan dan kinerja lalu lintas. Metode yang digunakan dalam penelitian observasi lapangan dan menggunakan data jumlah kecelakaan pada tahun 2018-2020 yang berlokasi di Jalan Raya Ngaliyan yang diambil dari data kecelakaan Satlantas Polsek Semarang Barat. Tingkat kinerja jalan pada ruas Jalan Tanjakan Silayur Kota Semarang, pada jam puncak pagi dan jam non puncak siang hari kategori $C$ dan pada jam puncak sore hari kategori E. Kerusakan permukaan lapis perkerasan lentur (flexible pavement) pada ruas Jalan Tanjakan Silayur didominasi oleh jenis kerusakan retak, alur, dan bleeding.
\end{abstract}


Salah satu faktor penyebab kecelakaan karena belum optimalnya rambu-rambu lalu lintas pada ruas Jalan Tanjakan Silayur.

Kata Kunci: Kecelakaan, Kecelakaan Lalu Lintas, Kemacetan Lalu Lintas.

\section{PENDAHULUAN}

Sistem transportasi diperlukan di wilayah metropolitan, untuk menjadi transportasi khusus yang dapat mengurangi kepadatan lalu lintas untuk bekerja dengan pengembangan transportasi keluar masuk kawasan metropolitan serta melayani kegiatan masyarakat di kota tersebut. Sarana dan prasarana trasportasi beserta sistem transportasi yang efektif diperlukan agar tidak ada atau mengurangi masalah transportasi seperti kemacetan. Perjalanan dalam kota salah satu jalan yang cukup crowded, berada di Jalan Raya Ngaliyan (Tanjakan Silayur). Kepadatan lalu lintas di pagi dan sore hari secara bertahap meningkat ketika daerah kota melakukan banyak kegiatan pada waktu ini (Ofyar \& Tamin, 2000). Peningkatan jumlah kendaraan yang beroperasi di jalan tidak seimbang dengan kapasitas jalan menjadi penyumbang penyebab kemacetan (Oktopianto \& Pangesty, 2021).

Faktor penyebab kemacetan adalah meningkatnya kecenderungan para pemakai jasa transportasi untuk menggunakan kendaraan pribadi dibandingkan dengan kendaraan umum (Alokabel, 2018). Kemacetan total terjadi apabila kendaraan bergerak sangat lamban atau bahkan berhenti. Bagaimanapun, perjalanan bersamaan ini menghasilkan arus lalu lintas yang besar, sehingga menjadikannya subjek untuk menyelidiki apa yang menyebabkan kemacetan tersebut. Tiga faktor penyebab kemacetan lalu lintas yaitu bertambahnya kendaraan bermotor, terbatasnya kemampuan dalam pembangunan jalan raya dan belum optimalnya pengoperasian transportasi massal (Dahlan, 2021) (Atho 'ur Rohman \& Kartikasari, 2016). Masalah lalulintas mulai dari besarnya jumlah penduduk, panjang jalan, banyaknya jumlah kendaraan dan Produk Domestik Regional Bruto (PDRB) (Medriosa, 2014).

Diperlukan manajemen rekayasa lalu lintas pada beberapa titik yang dianggap atau berpotensi dapat terjadi kemacetan seperti saat pagi dan sore hari (Abdul, 2012). Penataan struktur tata ruang dengan pembangunan infrastruktur jalan dan perbaikan manajemen lalu lintas, serta peningkatan kapasitas angkutan umum (Fauzi, 2021). Kemacetan timbul karena inkonsistensi lalu lintas kendaraan di semua aspek jalan dan berpotensi terjadinya kecelakaan lalu lintas yang mana dapat menyebabkan kerugian secara kondisi kesehatan dan financial para pengguna jalan. Oleh karena itu, lalu lintas yang tidak teratur memerlukan suatu penertiban jalur lalu lintas seperti pengaturan lalu lintas, misalnya aturan lalu lintas dari beberapa pihak terkait sehubungan dengan kendaraan, ruas jalan, dan dioptimalkannya jembatan penyebrangan.

Selain kemacetan lalu lintas masalah pada jalan adalah tingkat keselamatan lalu lintas. Keselamatan jalan merupakan bagian dari agenda kesehatan masyarakat dan agenda pembangunan perkotaan. Kecelakaan lalu lintas merupakan indikator utama tingkat keselamatan jalan raya (Oktopianto, Shofiah, et al., 2021). Kecepatan kendaraan memegang peranan yang penting dalam terjadinya kecelakaan. Penyebab kecelakaan ada 3 faktor utama, yaitu manusia, kendaran, dan jalan (Oktopianto, Nabil, et al., 2021). Tingginya mobilitas yang semakin meningkat dari tahun ke tahun tentunya akan menjadi sebuah permasalahan transportasi jalan di masa depan jika tidak dilakukan penanganan yang tepat (Oktopianto, Prasetyo, et al., 2021). Melihat banyaknya permasalahan transportasi di atas tujuan dari penelitian ini adalah untuk 
menganalisis kinerja Jalan, kerusakan jalan dan keselamatan jalan pada ruas Jalan Raya Ngaliyan Kota Semarang Tanjakan Silayur.

\section{METODE PENELITIAN}

Dalam penelitian ini menggunakan data primer dan data skunder yang diambil dari pihak yang terkait dari tujuan penelitian. Sumber yang didapatkan di lapangan saat survey akan menjadi acuan dasar data primer. Data primer berupa informasi penting yang dapat melengkapi informasi yang dibutuhkan dalam penelitian. Pengumpulan data langsung di lapangan dengan survei di area penelitian, yaitu pada ruas Jalan Raya Ngaliyan. Data sekunder didapatkan dari internet melalui aplikasi Google Maps yang berupa peta Ruas Jalan Raya Ngaliyan, dan beberapa data dari Dinas Perhubungan Provinsi Jawa Tengah yang meliputi data volume kendaraan ratarata dan data kecelakaan dari Satlantas Polsek Semarang Barat yang berupa jumlah data kecelakaan pertahun. Tahapan yang dilakukan dalam penelitian ini adalah sebagai beriku:

1. Studi literatur, yaitu melakukan tinjauan terkait kemacetan dan kecelakaan jalan raya

2. Pengumpulan data sekunder yang meliputi lokasi penelitian dan volume kendaraan rata-rata

3. Pengumpulan data primer yang terdiri dari volume harian, kecepatan lalu lintas dan kerusakan jalan

4. Analisis kepadatan lalu lintas

5. Analisis kapasitas jalan

6. Analisis kerusakan jalan

7. Analisis Keselamatan jalan

8. Hail analisis, kesimpulan berupa rekomendasi penanganan

\section{HASIL DAN PEMBAHASAN}

\section{a. Kondisi Geometrik Jalan}

1. Karakteristik Jalan $=4$ lajur 2 arah terbagi (4/2D)

2. Lajur jalan kanan $=3,6$ meter

3. Median jalan $=1,2$ meter

4. Trotoar kiri $=0,80$ meter

5. Lajur jalan kiri $=3,4$ meter

6. Damija $=16$ meter

7. Lebar jalan total $=14$ meter

\section{b. Volume Lalu Lintas Rata-Rata Jam Puncak Pagi}

Pada jam puncak pagi hari di lokasi pengamatan jumlah arus lalu lintas rata-rata perhari adalah 4.699,06 smp/jam. Jumlah arus lalu lintas rata-rata per hari dari utara ke arah selatan adalah $1.593,4 \mathrm{smp} / \mathrm{jam}$, sedangkan arus lalu lintas rata-rata per hari dari selatan ke arah utara sebesar 3.105,4 smp/jam. Pada jam non puncak siang hari di lokasi pengamatan jumlah arus lalu lintas rata-rata perhari adalah 3.656,3 smp/jam. Arus lalu lintas rata-rata per hari ke arah barat sebesar 1.940,3 smp/jam sedangkan jumlah arus lalu lintas rata-rata per hari ke arah timur adalah $1.716,6 \mathrm{smp} / \mathrm{jam}$. Jadi arus lalu lintas rata-rata terbesar arah ke barat dengan nilai 1.940,3 smp/jam. 


\section{Volume Lalu Lintas Rata-Rata Jam Puncak Pagi}

Pada jam puncak sore hari di lokasi pengamatan jumlah arus lalu lintas rata-rata perhari adalah 5.711,3 smp/jam. Arus lalu lintas rata-rata per hari ke arah utara sebesar 2.590,8 smp/jam, sedangkan jumlah arus lalu lintas rata-rata per hari ke arah Selatan adalah 3.120,4 smp/jam. Sehingga dapat disimpulkan bahwa volume lalu lintas di sore hari sekitar pukul 16.00-18.00 lebih besar ke arah selatan 529,6 smp/jam dibandingkan volume kendaraan ke arah utara.

\section{d. Kepadatan Lalu Lintas}

Kepadatan lalu lintas merupakan banyaknya kendaraan yang melewati sepanjang jalan suatu jalur yang umumnya disebut sebagai jumlah kendaraan per kilometer. Di bawah ini merupakan perhitungan kepadatan lalu lintas:

Kepadatan lalu lintas: $\mathrm{k}=\frac{\mathrm{q}}{\mathrm{s}}$

K: kepadatan lalu lintas (kendaraan/kilometer); q: jumlah kendaraan pada ruas jalan yang diamati (kendaraan/jam); s: kecepatan lalu lintas (kilometer/jam)

1. Kepadatan lalu lintas pada hari senin:

a. Arah Utara

$$
\begin{aligned}
& k=\frac{7.658,5}{56,33} \\
& k=136 \mathrm{kend} / \mathrm{km}
\end{aligned}
$$

b. Arah Selatan

$$
\begin{aligned}
& k=\frac{6.841}{60,67} \\
& k=113 \text { kend } / k m
\end{aligned}
$$

2. Kepadatan lalu lintas pada hari kamis:

a. Arah Utara

$$
\begin{aligned}
& k=\frac{18 \cdot 240,5}{42,66} \\
& k=428 \mathrm{kend} / \mathrm{km}
\end{aligned}
$$

b. Arah Selatan

$$
\begin{aligned}
& \mathrm{k}=\frac{14.449,5}{46,84} \\
& \mathrm{k}=308 \mathrm{kend} / \mathrm{km}
\end{aligned}
$$

3. Kepadatan lalu lintas pada hari minggu:

a. Arah Utara

$$
\begin{aligned}
& k=\frac{17 \cdot 241,5}{17 \cdot 241,5} \\
& k=301 \text { kend } / \mathrm{km}
\end{aligned}
$$

b. Arah Selatan

$$
\begin{aligned}
& k=\frac{13.926,5}{52,64} \\
& k=265 \mathrm{kend} / \mathrm{jam}
\end{aligned}
$$


Diketahui bahwa kepadatan maksimum berada pada hari kamis di ruas jalan yang menuju ke arah utara dengan angka $428 \mathrm{kend} / \mathrm{km}$, dan kepadatan minimum terjadi pada hari senin di ruas jalan yang menuju ke arah selatan dengan angka 113 kend/km. Sedangkan untuk hari minggu memiliki kepadatan yang hampir sama dengan hari senin, dengan kepadatan arah utara di angka $301 \mathrm{kend} / \mathrm{jam}$ dan ke arah salatan di angka $265 \mathrm{kend} / \mathrm{jam}$.

\section{e. Kapasitas}

Kapasitas dasar ditentukan dengan kondisi geometrik jalannya, pada ruas Jalan Ngaliyan Silayur diketahui kondisi eksistingnya 4 lajur 2 arah terbagi. Sehingga diketahui kapasitas dasar (Co) adalah $6.600 \mathrm{smp} / \mathrm{jam}$. Nilai kapasitas ruas Jalan Silayur dapat dilihat pada Tabel 1 berikut ini :

Tabel 1. Kapasitas Sesungguhnya Jalan Ngaliyan Silayur

\begin{tabular}{clc}
\hline No & \multicolumn{1}{c}{ Faktor Analisis } & Nilai \\
\hline 1 & Kapasitas dasar (Co) smp/jam & 6.600 \\
2 & Faktor penyesuaian lebar jalur (FCw) & 1,00 \\
3 & $\begin{array}{l}\text { Faktor penyesuaian akibat pemisah arah } \\
\text { (FCsp) }\end{array}$ & 1,00 \\
4 & Faktor penyesuaian hambatan samping (FCsf) & 0,95 \\
5 & Faktor penyesuaian ukuran kota (FCcs) & 1,00 \\
& Kapasitas (C) smp/jam & 6.270
\end{tabular}

Kapasitas sesungguhnya Jalan Ngaliyan Silayur mempunyai kapasitas dasar (Co) 6.600, faktor perubahan lebar jalur (FCW) 1,00, faktor perubahan pemisah jalur (FCsp) 1,00 , faktor perubahan hambatan samping (FCsf) 0,95 , faktor perubahan ukuran kota (FCcs) 1,00, dan dengan kapasitas (C) smp/jam senilai 6.270. Pada ruas Jalan Silayur (Ngaliyan) volume kendaraan terbesar hanya pada jam-jam sibuk saja.

\section{f. Derajat Kejenuhan}

Nilai DS pada ruas Jalan Ngaliyan sendiri dapat ditentukan menggunakan derajat kejenuhan (DS). Sehingga tingkat pelayanan pada ruas Jalan Silayur dapat diketahui pada Tabel 2 di bawah ini:

Tabel 2. Tingkat Pelayanan Berdasarkan Nilai DS

\begin{tabular}{ccc}
\hline Waktu & $\begin{array}{c}\text { Derajat Kejenuhan } \\
\text { (DS) }\end{array}$ & Tingkat Pelayanan \\
\hline Jam Puncak Pagi Hari & 0,75 & $\mathrm{C}$ \\
$07.00-09.00$ & & $\mathrm{C}$ \\
Jam Non Puncak Siang \\
Hari & 0,58 & \\
$\begin{array}{c}12.00-14.00 \\
\text { Jam Puncak Sore Hari }\end{array}$ & 0,91 & $\mathrm{E}$ \\
$16.00-18.00$ & & \\
\hline
\end{tabular}


Berdasarkan data nilai DS yang sudah diperoleh, maka dapat diketahui tingkat pelanyanan pada Jalan Ngaliyan Kota Semarang, diantaranya:

a. Pada jam puncak pagi hari diketahui nilai DS sebesar 0,75. Kemudian pada titik tersebut sangat terlihat bahwa tingkat pelayanan berada pada klasifikasi $\mathrm{C}$ yang berarti arus lalu lintas stabil namun kecepatan dan pergerakan kendaraan dipengaruhi oleh volume lalu lintas.

b. Pada jam non puncak siang hari diketahui nilai DS sebesar 0,58 . Kemudian pada titik tersebut sangat terlihat bahwa tingkat pelayanan berada pada klasifikasi $\mathrm{C}$ yang berarti arus lalu lintas stabil namun kecepatan dan pergerakan kendaraan dipengaruhi oleh volume lalu lintas.

c. Pada jam puncak sore hari diketahui nilai DS sebesar 0,91. Kemudian pada titik tersebut sangat terlihat bahwa tingkat pelayanan berada pada klasifikasi $\mathrm{E}$ yang berarti volume lalu lintas mendekati batas yang dapat dipenuhi oleh ruas jalan, arusnya goyah, dan kecepatan sesekali berhenti dengan alasan bahwa volume lalu lintas terlalu tinggi.

\section{g. Kerusakan Jalan}

Selain kerusakan jalan alur, kerusakan jalan lain yang terdapat pada ruas Jalan Raya Ngaliyan adalah kerusakan jalan gelombang, kerusakan jalan gelombang terdapat di Tanjakan Ngaliyan. Kerusakan jalan gelombang pada ruas Jalan Raya Ngaliyan ini disebabkan dari beberapa faktor antara lain seperti tingkat kebisingan yang rendah dari campuran yang dapat muncul dari tingkat penggunaan kadar aspal yang tidak bagus, penggunaan agregat halus yang berlebih, agregat bulat dan licin, serta penggunaan aspal yang memiliki infiltrasi tinggi.

\section{h. Keselamatan Jalan}

Pada ruas Jalan Raya Ngaliyan kerap terjadi kecelakaan lalu lintas maka akan dilakukan penambahan pemasangan rambu-rambu dan papan peringatan bagi pengendara yang melintas di jalan yang rawan kecelakaan lalu lintas. Setelah rambu- rambu larangan bagi truk bermuatan diatas delapan ton dilarang melintas pada jam- jam tertentu, juga sekaligus melakukan penegakan aturannya dengan penindakan. Sedangkan untuk upaya penanganan jangka Panjang, yaitu berkoordinasi dengan instansi terkait mendorong pengurangan elevasi atau pengeprasan jalan, bisa dikurangi karena saat ini cukup curam yaitu diatas enam persen.

Berdasarkan hasil pengolahan data yang telah dilakukan di lapangan dan yang sudah pernah dilakukan sebelumnya, di dapatkan beberapa data yang kiranya dapat menjadi penyebab terjadinya kemacetan dan kecelakaan di Jalan Raya Ngaliyan. Menurut penelitian sebelumnya diperlukan manajemen rekayasa lalu lintas karena jalan termasuk dalam kategori kelas hambatan samping sangat tinggi (Abdul, 2012), sedangkan dari hasil analisis memberikan kesimpulan bahwa dikarenakan pada ruas jalan tersebut jumlah sepeda motor paling mendominasi daripada kendaraan lainnya. Pada Kinerja Ruas Jalan Waturenggong di Kota Denpasar Ruas jalan tidak mampu lagi menampung kapasitas arus lalu lintas (Abdul, 2012), sedangkan pada Jalan Silayur 
Ngaliyan masih mampu melayani volume kendaraan pada saat jam puncak dan masih jauh dari batas yang izinkan. Kapasitas dan kinerja jalan pada ruas jalan Silayur Ngaliyan volume kendaraan terbesar hanya pada jam-jam sibuk saja. Kinerja jalan Margonda Raya Kota Depok arus mendekati tidak stabil dan kecepatan masih dapat dikendalikan (Susilowati, 2019), tetapi pada ruas jalan Silayur Ngaliyan masih bisa dikendalikan dengan cara memberi arahan untuk menempatkan setiap petugas berwajib pada titik yang dianggap cenderung mengalami kemacetan seperti saat pagi dan sore hari.

Kerusakan permukaan lapis perkerasan lentur (flexible pavement) pada ruas Jalan Tanjakan Silayur didominasi oleh jenis kerusakan retak, alur, dan bleeding. Keselamatan lalu lintas dapat dilakukan dengan cara memasang rambu-rambu lalu lintas di sisi jalan yang dapat terlihat lebih jelas agar pengendara dapat melihat rambu dengan jelas sehingga pengguna jalan dapat lebih berhati-hati dan waspada saat mengemudi.

\section{SIMPULAN}

Berdasarkan analisa yang sudah diperoleh, dapat diketahui tingkat kinerja jalan pada ruas Jalan Tanjakan Silayur Kota Semarang pada jam puncak pagi dan jam non puncak siang hari tingkat pelayanan masuk dalam klasifikasi kategori $C$ yang berarti arus lalu lintas stabil namun kecepatan dan pergerakan kendaraan dipengaruhi oleh volume lalu lintas. Pada jam puncak sore hari diketahui tingkat pelayanan masuk dalam kategori E yang berarti volume lalu lintas mendekati kapasitas yang dapat ditampung ruas jalan tersebut, arus tidak stabil, dan kecepatan kadang berhenti karena volume lalu lintasnya yang terlampau tinggi.

Kerusakan permukaan lapis perkerasan lentur (flexible pavement) pada ruas Jalan Tanjakan Silayur didominasi oleh jenis kerusakan retak, alur, dan bleeding. Berdasarkan pengamatan di lapangan, kerusakan disebabkan oleh tingginya volume kendaraan berat (overload) yang melintasi ruas jalan ini karena ruas jalan ini merupakan salah satu rute kendaraan besar untuk menuju kawasan Bukit Semarang Baru (BSB). Kerusakan yang terjadi juga disebabkan karena tidak diimbanginya peningkatan konstruksi jalan secara signifikan untuk menerima beban lalu lintas yang tinggi. Selain itu, ruas jalan ini tidak didukung dengan sistem drainase yang memadai.

Salah satu faktor penyebab kecelakaan karena belum optimalnya rambu-rambu lalu lintas pada ruas Jalan Tanjakan Silayur Kota Semarang, sehingga keselamatan lalu lintas dapat dilakukan dengan cara memasang rambu-rambu lalu lintas agar pengendara dapat berhati-hati dalam berkendara. Diperlukan adanya rambu lalu lintas untuk keselamatan di sepanjang ruas Jalan Tanjakan Silayur Kota Semarang seperti turunan curam yang berfungsi untuk mengingatkan pengguna jalan agar lebih berhatihati terhadap potensi risiko saat persimpangan jalan menanjak. 


\section{DAFTAR PUSTAKA}

Abdul, A. R. (2012). Analisis Kinerja Ruas Jalan Raja Eyato Di Kota Gorontalo. 2(2), 89-95.

Alokabel, K. (2018). ANALISA KINERJA PERSIMPANGAN TAK BERSINYAL TIPE T PADA PERTEMUAN RUAS JALAN TIMOR RAYA DAN JALAN SURATIM DI KELURAHAN OESAPA KECAMATAN KELAPA LIMA KOTA KUPANG PROVINSI NUSA TENGGARA TIMUR. JUTEKS - Jurnal Teknik Sipil, 3(1). https://doi.org/10.32511/juteks.v3i1.194

Atho 'ur Rohman, M., \& Kartikasari, D. (2016). ANALISA KEMACETAN LALU LINTAS PADA PASAR TRADISIONAL DI RUAS JALAN SEKARAN-MADURAN. $J$ u $r \mathrm{n}$ a / $C$ I $V I L L a V o / 1$ No 2 S e p t e m b e $2016,1(2)$.

Dahlan, E. (2021). Evaluasi Kecepatan Rata-Rata terhadap Kendaraan Arus Bebas (Studi Kasus: Jalan Kolonel Abunjani Kota Jambi). Jurnal Talenta Sipil, 4(2). https://doi.org/10.33087/talentasipil.v4i2.78

Fauzi, M. (2021). Metode Headway Dllaj Dan Bok Bep Di Masa Pandemi Covid-19. $16(2), 85-92$.

Medriosa, H. (2014). Netode Cluster Analysis. Jurnal Momentum, 16(2).

Ofyar, \& Tamin. (2000). Perencanaan dan Permodelan Transportasi. ITB.

Oktopianto, Y., Nabil, M. J., \& Arief, Y. M. (2021). SOSIALISASI KESELAMATAN TRANSPORTASI JALAN PENGEMUDI GOJEK DI KOTA TEGAL. Kumawula: Jurnal Pengabdian Kepada Masyarakat, 4(2), $242 \quad$ - 248. https://doi.org/10.24198/kumawula.v4i2.33321

Oktopianto, Y., \& Pangesty, S. (2021). Analisis Daerah Lokasi Rawan Kecelakaan Jalan Tol Tangerang-Merak. Jurnal Keselamatan Transportasi Jalan (Indonesian Journal of Road Safety), 8(1), 26-37. https://doi.org/10.46447/ktj.v8i1.301

Oktopianto, Y., Prasetyo, T., \& Maulana Arief, Y. (2021). Analisis Penanganan Daerah Rawan Kecelakaan Kabupaten Karanganyar. Borneo Engineering: Jurnal Teknik Sipil, 5(2), 201-214. https://doi.org/10.35334/be.v5i2.2018

Oktopianto, Y., Shofiah, S., Rokhman, F. A., Wijayanthi, K. P., \& Krisdayanti, E. (2021). Analisis Daerah Rawan Kecelakaan (Black Site) Dan Titik Rawan Kecelakaan (Black Spot) Provinsi Lampung. Borneo Engineering: Jurnal Teknik Sipil, 5(1), 40-51. https://doi.org/10.35334/be.v5i1.1777

Susilowati, E. (2019). Analisa Kinerja Jalan Margonda Raya Kota Depok. Journal of Chemical Information and Modeling, 53(9), 1689-1699. 